\title{
THE ROLE OF LEXICAL FREQUENCY IN MODERATING THE EFFECT OF GRAMMAR KNOWLEDGE ON L2 READING OUTCOMES ${ }^{1}$
}

\author{
Sahiruddin \\ (shrdn@ub.ac.id) \\ Universitas Brawijaya \\ Jl. Veteran, Lowokwaru, Malang, East Java, Indonesia, 65145
}

\begin{abstract}
Sentence-level grammar skills are of the important foundations in the mastery of reading skills in second language (L2). Previous studies showed inconclusive findings about the effect of grammar knowledge on L2 reading. This study examines the relationship between L2 reading outcomes and reader-based grammar knowledge as it is moderated by text-based features of vocabulary difficulty. Participants were EFL students $(n=71)$ in the second year of their English major at an Indonesian university. The participants' grammar knowledge was measured using a test of sentence-level grammatical knowledge. Text-based vocabulary difficulty was assessed using VocabProfile software (Cobb, 2010). During the data collection period, the participants completed four reading texts, each reflecting a unique combination of two levels (high vs. low) of lexical frequency. This study reveals that reader grammar knowledge influenced L2 reading outcomes. It also shows that text vocabulary difficulty significantly moderated the relationship between reader grammatical knowledge and $\mathrm{L} 2$ reading, indicating that the relationship between grammar knowledge and L2 reading for high lexical frequency texts was significantly greater than for low lexical frequency texts.
\end{abstract}

Keywords: vocabulary, lexical frequency, grammar knowledge, L2 reading outcomes, text features, moderation

DOI: http://dx.doi.org/10.15639/teflinjournal.v29i2/194-218

\footnotetext{
${ }^{1}$ This article is based on a paper presentation at the $65^{\text {th }}$ TEFLIN International Conference at Universitas Negeri Makassar on 12-14 July 2018.
} 
It is widely acknowledged that reading comprehension is a critical skill in L2 academic contexts (Anderson, 1984; Grabe, 2009; Richards \& Renandya, 2002; Stanovich, 1986). In Indonesia, reading is the primary focus of English language teaching at the secondary and tertiary levels (Cahyono \& Widiati, 2006). The emphases are commonly on developing reading competence and providing students with opportunities to gain insights into English-speaking cultures (Masduqi, 2014). However, despite the focus on reading, students' learning outcomes in in this aspect are generally low at both secondary (Murtiningsih, 2014, p. 3) and tertiary levels (Nurweni \& Read, 1999; Sahiruddin, 2008).

There are ranges of potential factors responsible for the current state of affairs. These include learners' attitudes to reading and English more generally (see Sadtono, 1997), motivation (see Kweldju, 1996), text genres (see Rukmini, 2004), teaching methods (see Cahyono \& Widiati, 2006) and L1 reading and literacy practices (see Rusfandi, 2013). In addition, as I have argued elsewhere, Indonesian learners' shortcomings in English vocabulary and grammar skills are a significant source of reading difficulty (Sahiruddin, 2008). In fact, readers' linguistic knowledge constitutes the most important factor determining the success in L2 reading (Anderson, 1984; Stanovich, 1986). As Grabe (1991, p. 280) asserts, "fluent readers need a sound knowledge of language structure and a large recognition of vocabulary". In practice, the contribution of readers' linguistic knowledge in reading outcomes sometimes is not evident. Thus, in this article, I would like to explore more on the role of text-based features on moderating the effect of readers' linguistic knowledge on L2 reading outcomes.

Reading has been modeled in many ways. The bottom-up model was one of the earliest models. Influenced by behaviorist theory in the $1950 \mathrm{~s}$, reading in the bottom-up perspective was purely a linear process in which readers decoded a text letter-by-letter, word-by-word, linking the words into phrases and sentences, and discourse level (Gough, 1972). The role played by vocabulary in this model is essential for comprehension and the role of grammar is ignored. In the late 1960s and 1970s, top-down models appeared. These approaches emphasized comprehension processes, particularly the role of cognitive processing and background knowledge on reading comprehension (Goodman, 1967; Smith, 1988). This framework emphasizes that the source of meaning construction is the stored knowledge in a reader's own mind, and sentence level processes and other textual processes received limited attention in text comprehension. 
Currently there is the general recognition that complete reading models need to incorporate both bottom-up and top-down elements; that is, they need to be interactive. Reading is assumed to involve the interaction between the elements of bottom-up and top-down processes required to support each other in text comprehension. In addition, the context of information and background knowledge should also be strong in order to support the lower-level process, and predictions and inferencing about the text meaning improve as the wordlevel process is more efficient (Grabe, 2009, p. 89). In this framework, readers' grammatical and vocabulary knowledge are the most fundamental lower-level elements and serve as a bottleneck to higher-level reading comprehension processes. Inability to recognize words and their meanings in a text, in turn, affects the reader's ability to integrate words into phrases and clauses in a sentence, and eventually leads to reading failure. Reading outcomes are the result of interaction between reader knowledge, particularly linguistic knowledge, and text features (reader-text interaction) (Anderson, 2000; Kintsch, 1998).

The construction-integration (CI) model was an extension of interaction model developed by Kintsch (1998). It is a widely recognised model of discourse comprehension that is used as the comprehension framework for this article. The model posits that reading comprehension is a discourse comprehension process that involves a text-based construction model and a situational inferencing model in creating a coherent mental representation of the text. In text-based processing, propositional analyses via sentence analysis are regarded as the key building block for meaning development in comprehension. A proposition is an idea unit in every sentence in a text, and within this point of view word recognition and syntactic parsing are fundamental in understanding propositions in a text. The result of an idea from text-based processing should be integrated with the reader's knowledge about reality as discussed in the text to reach the complete meaning of the text. Kintsch's model proposes that there are four important components in reading: word recognition, syntactic parsing, proposition formation, and inferencing. The situation model itself is retrieved from long-term memory (background and domain knowledge) (Kintsch, 1998; Kintsch \& Rawson, 2005). The present study adopts the CI reading model as a primary theoretical reading model with an assumption that L2 reading consists of cognitive processes involving the interaction between lower-level processes (word and sentence-level processes) and higher-level processes (comprehension processes, such as extracting text meaning based on readers' domain knowledge) (Grabe, 2009, p. 14; Koda, 2005, p. 4). 
This study takes into account the idea proposed by Kintsch (1998) and Anderson (2000) that reading outcome or comprehension is a result of the interaction between reader characteristics and text features. The term reader characteristics is used to describe entailing abilities, skills, knowledge, and experience of the readers used to comprehend the text. These reader characteristics include cognitive (attention, memory, and reasoning), linguistic, and nonlinguistic knowledge such as knowledge of the world (Snow \& Sweet, 2003). Reader characteristics are important sources of individual differences in text comprehension as good readers typically have a wider range of abilities and skills when compared to poor readers (Kintsch, 1994). It is important to note that this study uses the term reader knowledge rather than reader characteristics to specifically refer to linguistic knowledge in terms of grammatical knowledge. Meanwhile, text features are linguistic features carried in the texts such as lexical and syntactic difficulty levels (Chall \& Dale, 1995, Dubay, 2004, Flesch, 1951). These features are independent of the knowledge the reader brings to the text and are the characteristics of the text itself.

A number of studies have investigated reader knowledge factors (see, e.g., Anderson, 1984; Barrot, 2013; Jeon \& Yamashita, 2014; Laufer, 1992; Nassaji, 2003). These studies found L2 linguistic knowledge, including primarily grammatical knowledge that readers brought to a reading text or task, has significant effects on L2 reading. However, less research has explored the role of variability in text features in affecting this relationship in the L1 or L2. Studies on text-based features were mainly derived from text complexity or text readability research, where texts were assessed in terms of their complexity levels particularly in terms of lexical and syntactic complexity levels (Chall \& Dale, 1995; Flesch, 1951; Nelson, Perfetti, Liben, \& Liben, 2012). It was evident that text complexity levels did play an essential role in assisting learners to comprehend a text. Meanwhile, how reader knowledge relates to text features in predicting L2 reading outcomes has been largely neglected in L2 reading research. The research reported in this study, therefore, examines the interaction between reader knowledge and text features and their impact on L2 reading outcomes.

Grammatical knowledge has been theoretically argued to contribute to L1 and L2 reading outcomes (Bernhardt, 2011; Grabe, 2009). In reading research, different terminologies are used to refer to grammatical knowledge, including syntactic awareness, syntactic knowledge, syntactic/sentence processing, and syntactic parsing (Jeon \& Yamashita, 2014, p. 165). In this study, grammatical knowledge is defined as the knowledge of formedness (or ill-formedness) of a 
sentence or subparts of a sentence such as a clause or phrase (Shiotsu \& Weir, 2007, p. 106). It is knowledge of sentence structures and of acceptable syntactic sequences and forms of words. This knowledge enables readers to analyze and integrate syntactic information at the phrase, clause, and sentence levels within texts. Shiotsu (2010) also defines grammatical knowledge as "knowledge of sentence structures and that of acceptable sequences and forms of words in terms of syntax" (p. 61). Grammatical knowledge in this study is defined as the ability to identify correct sentence structures and was measured using the structure section of the paper-based TOEFL tests. This will be discussed further in the Method section.

Apart from theoretical construct on the role of grammar or grammatical knowledge on L2 reading, empirical research evidence on the role of grammatical knowledge in L2 reading has been inconclusive (Nassaji, 2007; Shiotsu \& Weir, 2007). For instance, Lopez (2008) found that grammatical knowledge is correlated with reading outcome ( $r=.47$ to .55$)$ for 186 Spanish university students. Nassaji (2003) found a moderate relationship between grammatical knowledge and L2 reading for L2 learners with Persian as their L1 $(r=.44)$. Lack of correlation between grammatical knowledge and reading was noticed in Zhang's (2012) study; implicit grammar with .174-.336 and explicit grammar with .057 - .181. Van Gelderen et al. $(2004,2007)$ also found that grammatical knowledge did not have a significant effect with Dutch-speaking EFL learners after vocabulary and other variables were controlled for. These mixed findings about the effect of grammatical knowledge on L2 reading outcomes have motivated this study as to examine the extent to which the relationship between the two is moderated by textual lexical difficulty.

The mixed findings are due in part to a focus in the research on the relationship between reader knowledge and reading outcomes, while ignoring the possible contribution that variability in text demands may make to the observed relationship between reader knowledge and reading skill. One of the important textual features that make a text more or less demanding is the degree of lexical difficulty. These features are characteristics of the text itself and independent of the knowledge the reader brings to it. All things being equal, a reader with better grammatical knowledge should do better on more lexically demanding texts, but it is unclear whether this relationship shows the same pattern for a reader with less grammatical knowledge. For any given study the absence of correlation between learner knowledge (e.g., grammatical knowledge) and reading outcomes may be due either to the state of the reader's knowledge or 
the demands of the text, or some combination of the two. The main focus of this study in on the relationship between reader grammatical knowledge and reading outcomes, as well as the interaction between this relationship and text demands (i.e. lexical difficulty). Text demands have been operationalized and quantified in the L1 readability research.

Studies about these text features are mainly drawn from readability studies in which the level of difficulty of a text is measured using a readability formula and becomes the basis to predict reading outcomes. Quantitative analysis of text features using a readability formula has been considered to be a reliable indicator of potential reading difficulty (Koda, 2005, p. 109). Terminologically, the term text complexity has been interchangeably used with text difficulty or text readability, though text readability is mostly used in measurement formulas. In this view, text complexity refers to the advanced language expressions that affect how easy or difficult it is to understand a text either in spoken or written forms (Skehan, 2009). Text complexity is generally based on linguistic features at the word and sentence levels (Chall \& Dale, 1995). Text complexity refers to the difficulty of words and sentence structures in the texts affecting the ease of reading comprehension. Every text has a level of complexity or readability that affects the way the reader interacts with it. This study looks at how text dimensions or textual features are moderating factors in the relation between grammatical knowledge and reading comprehension.

Text complexity has been operationalized in a number of ways. Over fifty readability formulas have appeared. All include two language components: lexical difficulty and syntactic complexity. They include early and widely used readability approaches, including the Flesch Reading Ease Index (Flesch, 1948), Flesch-Kincaid Grade Level (GL) Score (Flesch, 1951), the Dale-Chall Readability Formula (Chall \& Dale, 1995), and the Fry Index (Fry, 1968, 1977). Some additional readability formulas have also been proposed including the Gunning FOG formula (Gunning, 1952), the Powers, Summer, Kearl Readability test, the Bormuth formula (Dubay, 2004), the Lexile Framework for Reading (Stenner, Horabin, Smith, \& Smith, 1988), the Coh-Metrix (Graesser, McNamara, \& Louwerse, 2011; Graesser, McNamara, Louwerse, \& Cai, 2004). In regard to the assessment of text lexical difficulty, lexical frequency (high lexical frequency vs. low lexical frequency) was measured via an online software program called VocabProfile at www.lextutor.ca (Cobb, 2010), which is widely used (Heatley \& Nation, 2002). VocabProfile bases its textual lexical profiling on the British National Corpus. Other options are Range (Heatley \& 
Nation, 2002) and AntWordProfiler (Anthony, 2014). This study employed VocabProfile to assess textual lexical difficulty via lexical frequency levels.

The role of lexical frequency in vocabulary learning and assessment is thought to be associated with vocabulary knowledge using lexical decision tasks (Yap, Balota, Sibley, \& Ratcliff, 2012) and an index of lexical complexity (Rayner \& Duffy, 1986). Words occurring more frequently in language tend to be recognized faster than less frequent words, for instance as reflected in shorter response times in lexical decision tasks and shorter eye-fixation latency in eye-movement tasks. Lexical frequency approaches to L2 vocabulary learning are based on the assumption that the more frequently used words will be the more easily learned (Palmer, 1917, as cited in Milton, 2007). The central place of frequency with specific reference to vocabulary (Milton, 2009) and in language learning in general has been recognized recently (Ellis, 2002) in terms of frequency-difficulty link. Lexical frequency is found to be by far the most robust predictor of language performance (Brysbaert, Buchmeier, Conrad, Jacobs, Bülte, \& Bühl, 2011; Murray \& Forster, 2004). High-frequency words are processed faster than low-frequency words, and this phenomenon is often known as the word frequency effect (FE) and is one of the most investigated phenomena in psycholinguistics. It has even been argued that lexical familiarity has a direct relationship to readers' knowledge about a topic and has a significant impact on comprehension (Kintsch, 1998; Smagorinsky, 2001).

This study assumed that the effect of reader grammatical knowledge on L2 reading outcomes was affected by the condition of lexical difficulty in the text. The effect of grammatical knowledge would be different between texts with low lexical difficulty and texts with high lexical difficulty. This then could explain the divergence of the findings about the role of grammatical knowledge in comprehending a text. The role of both reader and text features in predicting L2 reading provides an additional insight for $\mathrm{L} 2$ reading researchers about the nature of $\mathrm{L} 2$ reading development.

\section{METHOD}

This study examines how individual differences in L2 linguistic knowledge, operationalized as grammatical knowledge, interact with textual features in the form of lexical frequency in predicting reading comprehension outcomes. The study was quantitative in design. Seventy-one English study program students $(n=71)$ from a state university in East Java voluntarily partic- 
ipated in this study. Participants were from the second year of their English major at an Indonesian university, with intermediate or pre-advanced level proficiency as measured by the Test of English for International Communication (TOEIC) scores $(M=526, S D=187)$ with a $95 \%$ confidence interval of [496,556]. Participants completed a paper-based grammatical knowledge test and online reading tests. Grammatical knowledge was measured using a practice TOEFL structure and written expression test involving multiple-choice based sentence completion tasks and grammatical error correction tasks (Laboratorium Ilmu Humaniora Divisi Bahasa, 2014). The TOEFL grammar test has been validated as a test assessing grammatical knowledge (see Shiotsu \& Weir, 2007) and much research has led to the adoption of the TOEFL sentence structure test to assess grammatical knowledge (Shiotsu, 2010; Shiotsu \& Weir, 2007; Yamashita, 1999; Zhang, 2012).

Reading comprehension was assessed using material adapted and selected from the reading sections of published TOEFL tests (Davy \& Davy, 2002; Duffy \& Mahnke, 1998). These passages were selected from various topics out of fourteen passages taken from published TOEFL reading tests. A total of four texts of approximately 250 to 300 words in length were used in this study. The four text topics were about people's reaction to modern-day television ("Television"), the nature of aging and its processes ("Aging"), the development of American literature ("Literature"), and a woman named Susan who decided to move to New York from her small town ("Susan"). The four texts were systematically varied by lexical frequency (lexical difficulty): high lexical frequency (Televsion); low lexical frequency (Aging); low lexical frequency (Literature); and high lexical frequency (Susan). Text based vocabulary difficulty defined by the lexical frequency of occurrence was assessed using VocabProfile software (Cobb, 2010). Lexical frequency (high lexical frequency vs. low lexical frequency) was measured via an online software program called VocabProfile at www.lextutor.ca (Cobb, 2010), which is widely used (Heatley \& Nation, 2002). VocabProfile bases its textual lexical profiling on the British National Corpus. In the case of lexical frequency, VocabProfile scores below 85 were classified as low lexical frequency, and texts with higher VocabProfile scores were categorized as high lexical frequency. The difference between high-frequency and low-frequency texts in terms of word frequency levels was only about $5-6 \%$. While the difference is small, even a small increase in the number of difficult words may have had a significant effect on performance on the low-frequency texts (Brown, 2013). L2 research on lexical frequency or 
lexical coverage (see Hsueh-chao \& Nation, 2000; Laufer, 1989, 1992; Schmitt, Jiang, \& Grabe, 2011) suggested that small difference of lexical coverage (98-100\%) make a significant difference in reading comprehension.

All data of the study were analyzed using SPSS version 22. A Pearson product moment correlation analysis was conducted to assess the strength of association between the overall grammatical knowledge and overall reading performance. The analysis began by reporting the effect of reader grammatical knowledge on second-language reading outcomes. Then, the analysis of the effect of grammatical knowledge on second-language reading was calculated using regression models. Afterwards, the effect of lexical frequency levels on reading was described.

In order to examine the interaction between reader knowledge and textual features in predicting L2 reading outcomes, this study tested the interaction between reader-knowledge variables and text-feature variables in predicting reading outcomes, based on Hayes' (2013) regression-based model. Statistically, since interaction or interaction effect refers to the combined effects of two or more predictor variables on an outcome (Field, 2014, p. 395), to test the interaction between two predictor variables, a new interaction variable was created by multiplying scores of two predictor variables. In this respect, reader knowledge was regarded as an independent variable, textual features were a moderator variable, and reading scores were a dependent variable. This study looked at the degree to which text feature variables (lexical frequency) affected the relationship between reader linguistic knowledge (grammatical knowledge) and $\mathrm{L} 2$ reading outcomes.

\section{FINDINGS AND DISCUSSION}

\section{Findings}

This study generally finds that the effect of reader knowledge (as defined as grammatical knowledge) on L2 reading outcomes is significant. The grammar test results were normally distributed at skewness of $.542(S E=.28), \mathrm{Z}=$ $.542 / .28=1.94<1.96$ and kurtosis of $-.023(S E=.56), Z=.023 / .56=.04<$ 1.96 since the data were within the ranges of normal kurtosis and skewness as the values were not greater than 1.96 or 2.58 (Field, 2009, p. 139). The reliability of the test is toward the lower end of acceptability, Cronbach's alpha $=.75$. The mean score of grammatical knowledge was $M=47 \%, S D=4.8 \%$, indicat- 
ing that the grammar test was quite challenging for the participants. The lowest score on the grammar test was $37 \%$ and the highest was $61 \%$. The effect of grammatical knowledge on L2 reading was computed using a Pearson product moment correlation analysis. Grammatical knowledge was found to significantly correlate with $\mathrm{L} 2$ reading outcomes, $r=.56, p<.001$.

The reading test was an adapted TOEFL multiple-choice test in which each text was accompanied by five multiple-choice questions. The reliability for the reading test was .93 for item reliability and .51 for person reliability as analysed using a Rasch analysis. The reliability is above the minimum acceptable value of reliability of coefficient (Field, 2009). The reading texts and questions were adapted from published tests and thus were assumed to have been validated by the test developers. The reading test was scored by calculating the correct scores of twenty questions from performance on four reading texts. The reading test scores approximated a normal distribution as evident in the ranges for kurtosis $(-.342, S E=288) ; Z=-.342 / .288=-1.18<+/-1.96$. The descriptive statistics revealed that the participants' mean reading performance in this study was $38.7(S D=25)$.

In addition, this study also investigates the effect of text lexical frequency on reading outcomes. Lexical frequency is operationalized by the proportion of high- and low-frequency words in the respective text types as fixed by text complexity metrics used in readability research. Lexical difficulty was operationalized in terms of the relative frequency of occurrence of the words in the texts. Texts with more low-frequency words are assumed to be more difficult to read and understand (Nation, 2006). Lexical frequency in the four reading texts used in this study was calculated using the online VocabProfile software program, which is based on the British National Corpus (Cobb, 2010). Lexical frequency scores used here represent the percentage of high-frequency words in the text regardless of the level of syntactic complexity; texts with high scores contain more high-frequency words, and texts with lower scores contain more low-frequency words. The threshold for low-frequency words was words beyond 2,000 word levels (3,000-10,000 word frequency levels). Table 1 presents text lexical frequency scores and mean reading scores.

Table 1 shows that texts with high lexical frequency contained $88-89 \%$ of high-frequency words while texts with low lexical frequency consisted of 82$84 \%$ of high-frequency words. There were 17 low-frequency words in high lexical frequency texts and 35 low-frequency words in low lexical frequency texts. The texts ranged from 250 words to 300 words in overall length. 
Table 1. High (H) versus Low (L) Lexical Frequency Levels in the Four Reading Texts

\begin{tabular}{llll}
\hline Texts & $\begin{array}{l}\text { Frequency } \\
\text { level }\end{array}$ & Lexical frequency profile & Mean reading score \\
\hline Text 1 & HLF & 89 & $62(S D=2.5)$ \\
\hline Text 2 & HLF & 88 & $43(S D=2.6)$ \\
\hline Text 3 & LLF & 84 & $26(S D=2.4)$ \\
\hline Text 4 & LLF & 82 & $24(S D=2.1)$ \\
\hline
\end{tabular}

Note. HLF: high lexical frequency; LLF: low lexical frequency

Table 1 also shows that texts with higher lexical frequency influenced L2 reading outcomes as reflected in higher reading scores, as in Text 1 and Text 2 (Combined $M=53, S D=24$ ). On the other hand, a larger proportion of low lexical frequency items resulted in less accurate reading comprehension, as in Text 3 and Text $4(M=25, S D=19)$. An independent t-test was computed to see if the mean difference between the combined high lexical frequency texts and low lexical frequency texts was statistically significant. Levene's test of equality of variance indicated that the homogeneity of variance assumption was violated $(p<.001)$ so unequal variances were assumed for significance testing. The t-test revealed that reading performance for texts with high lexical frequency was significantly better than low lexical frequency texts, $t(282)=$ $10.95, p<.001$. The Cohen's $d$ effect size was 1.29 reflecting a large effect size. The correlation between lexical frequency and L2 reading outcome was $r$ $=.57, p<.001$, showing a relatively strong relationship between text lexical frequency and $\mathrm{L} 2$ reading.

It has been established that, for the participants here, reader grammatical knowledge was important in predicting L2 reading, and that text lexical frequency played a strong role in explaining variation in L2 reading comprehension. The research so far has looked at the two dimensions independently. The next phase of the analysis examined how reader knowledge interacts with text features to affect reading outcomes. A better understanding of how the two dimensions relate to each other will provide insights into how reader knowledge affects reading outcomes as a function of text demands. The interaction between reader knowledge and textual features was analysed using the moderation linear regression model in Hayes's (2013) PROCESS tool, as well as simple linear regression models. The potential contribution of textual features in moderating the strength of the relationship between reader knowledge and L2 reading will potentially provide a more complete picture of $\mathrm{L} 2$ reading perfor- 
mance as it is affected by the relationship and interaction between reader knowledge and textual features.

The interaction analysis for the effect of lexical frequency on differences in grammatical knowledge showed a significant effect for the predictor variables as well as an interaction between the two, the latter reflecting the complex pattern of results presented in Table 2 .

Table 2. Linear Model of Reading Outcomes with Lexical Frequency Level and Reader Grammatical Knowledge as Predictor Variables

\begin{tabular}{lllll}
\hline & $\boldsymbol{b}$ & $\boldsymbol{S E B}$ & $\boldsymbol{t}$ & $\boldsymbol{P}$ \\
\hline Constant & 38.73 & 1.15 & 33.65 & .000 \\
& {$[36.467,40.997]$} & & & \\
\hline Lexical frequency & 5.06 & 0.39 & 12.80 & .000 \\
& {$[4.285,5.842]$} & & & \\
\hline Grammatical knowledge & 1.73 & 0.23 & 7.42 & .000 \\
& {$[1.272,2.189]$} & & & \\
\hline Grammatical knowledge x lexical & 0.236 & 0.08 & 2.91 & .003 \\
frequency & {$[0.076,-0.396]$} & & & \\
\hline Note. $R^{2}=.44 .95 \%$ confidence intervals for b are in square brackets; b: unstandardised
\end{tabular}
beta.

A simple slopes analysis is presented in Figure 1, and it shows that grammatical knowledge played a greater role in the high lexical frequency comparison $(b=.2 .41, p=.000)$ than in the low-frequency comparison $(b=.1 .05, p=$ .006). This was also reflected in simple linear regression that showed that grammatical knowledge differences accounted for $22 \%$ of the reading variance for high-frequency texts and $8 \%$ for the low-frequency texts. The differences in readers' grammatical knowledge were more evident in the high lexical frequency texts, suggesting that the use of grammatical knowledge is affected by the lexical demands of the text. 


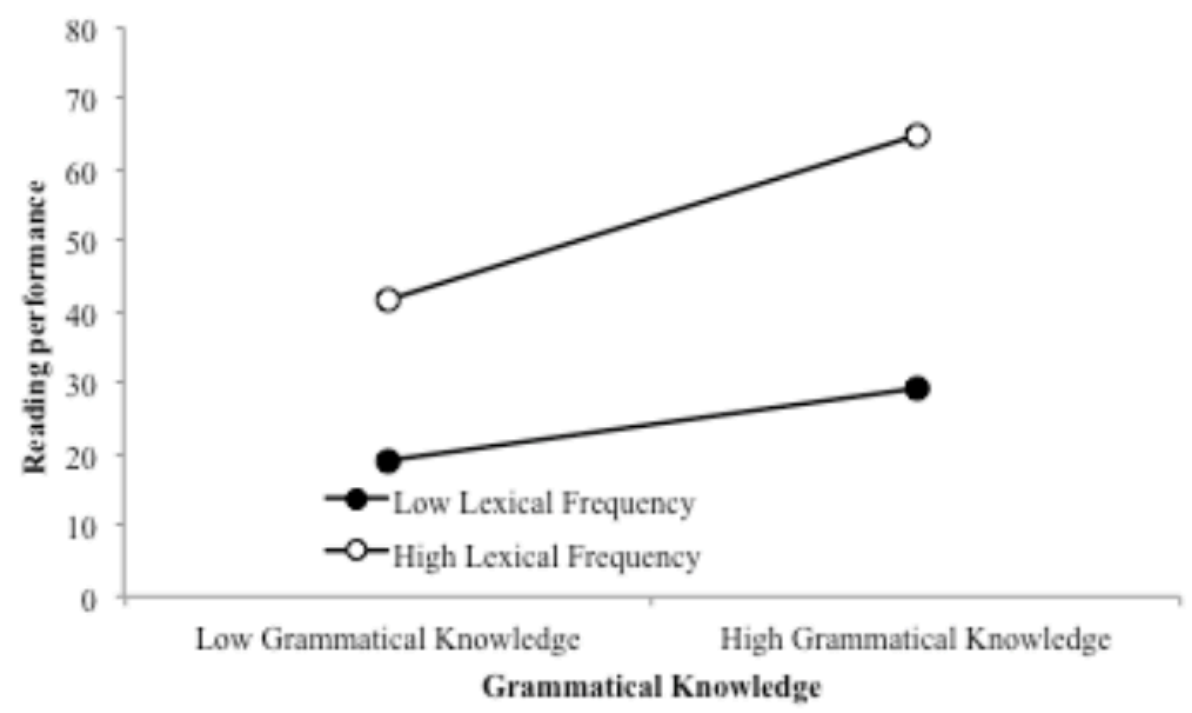

Figure 1. A Visual Representation (Simple Slopes) of the Interaction Effect of Grammatical Knowledge on Reading Comprehension at Two Levels of Lexical Frequency

\section{Discussion}

The main goal of the study is to examine the relationship between reader knowledge (grammatical knowledge) and textual features (lexical frequency) on second-language reading outcomes by Indonesian learners of English as a foreign language. This chapter discusses the findings on the relative contribution of grammatical knowledge to reading, the impact of text lexical difficulty on reading, and finally the potential effect of textual features in moderating the strength of the relationship between reader knowledge and reading outcomes.

This study has revealed the medium effect of grammatical knowledge on L2 reading outcomes $(r=.56)$. The relationship between grammatical knowledge and L2 reading outcomes found here was similar to that reported in Lopez's study (2008) with $r=.47$ to .55 for 186 Spanish university students and was slightly higher than the one reported in Nassaji's study (2003) for L2 learners with Persian as their L1 $(r=.44)$ and Zhang's (2012) study; implicit 
grammar with $.174-.336$ and explicit grammar with $.057-.181$. Van Gelderen et al. $(2004,2007)$ also found that grammatical knowledge did not have a significant effect with Dutch-speaking EFL learners after vocabulary and other variables were controlled for. Alternatively, a meta-analysis of 56 studies in L2 settings by Jeon and Yamashita (2014) reported a slightly stronger role of grammatical knowledge in reading outcomes, that is, .85 for grammar, which is higher than the one found in this study. Some possible explanations can be offered as to why the predictive power of grammatical knowledge on reading outcomes is not so high in this study. It may reflect the participants' difficulty in recognizing the words in the text. This potential interaction has been examined in this study. Besides, the grammatical test used in this study may have been too difficult for the participants, as reflected in their low performance in the test $(M=47, S D=4.8)$. A grammatical test with a greater range of difficulty might provide a more sensitive measure. This should be addressed in future research.

An essential correlation between a reader's grammatical knowledge and text comprehension is not surprising. Extensive research has shown that sufficient grammatical knowledge is required to read texts successfully (Grabe, 1991, p. 379). In addition, Anderson (2000) notes the importance of grammatical knowledge in L2 reading, stating that the ability to parse a sentence into its correct syntactic structure appears to be an important element in understanding texts. Learners with better grammatical knowledge are more likely to be able to successfully read and comprehend a text. Grammatical knowledge is essential in text comprehension as it drives syntactic parsing, an important element in establishing the propositional meanings of a text (Anderson, 2000; Fender, 2001; Kintsch, 1998).

Another concern of this study was whether textual lexical difficulty also predicted reading outcomes. It is independent of the linguistic knowledge the reader brings to the text. Lexical difficulty features have been shown to reliably affect the accessibility of the text to the reader (Linderholm, Everson, van den Broek, Mischinski, Crittenden, \& Samuels, 2001). The current study established that lexical frequency, as an index of lexical difficulty, played a great role in explaining the variation of reading scores $(r=.57)$. The findings can be interpreted in terms of the established link between frequency and difficulty; high-frequency words are more familiar to learners than low-frequency words (Brown, 2012; Ellis, 2002; Milton, 2007), and provide further support for lexical frequency as a robust predictor of language performance (Brysbaert et al., 
2011; Murray \& Forster, 2004). This study also demonstrates the construct validity of lexical frequency as an index of text difficulty (Read, 2000).

The difference between high-frequency and low-frequency texts in terms of word frequency levels was only about $5-6 \%$. While the difference is small, even a small increase in the number of difficult words may have had a significant effect on reading comprehension (Brown, 2013). This finding supports previous research about the importance of understanding words in the text or lexical coverage (Laufer, 1989, 1992; Hsueh-chao \& Nation, 2000; Schmitt, et al., 2011). For instance, Schmitt et al.'s (2011) study with 661 L2 advanced learners from Turkey, China, Spain, Israel, Great Britain, Japan, and Sweden found that in order to get $60 \%$ comprehension, learners were required to understand $95 \%$ of vocabulary coverage. A $98-99 \%$ coverage was required to reach $70 \%$ comprehension, and $75 \%$ comprehension was associated with recognizing all of the words in the text. High lexical coverage (98-100\%) is critical, but insufficient, for complete reading comprehension.

Most importantly, this study investigates how the potential effect of grammatical knowledge on reading outcomes is moderated by textual demands. It assumes that success or failure in comprehending a given reading text depends importantly on the knowledge - grammatical - that the learner brings to the task, but that the relative importance of that knowledge will depend on text demands arising out of the lexical difficulty of the text. The potential interaction effect between learner knowledge and text demands is conceptually operationalized as a moderation effect (Field, 2014; Hayes, 2013). A moderation is defined as the presence of a variable that affects the direction and/or strength of the relationship between an independent and a dependent variable (Baron \& Kenny, 1986). In statistical terms reading outcomes were predicted from reader knowledge (vocabulary size and grammatical knowledge) and the proposed moderators or textual features (lexical difficulty and syntactic complexity), and the interaction of the two variables. The interaction of the two variables is simply the scores of reader knowledge and textual features multiplied together. If the interaction is significant, then moderation is evident. This study employed Hayes' (2013) PROCESS tool that is based on a linear regression model to calculate the interaction (moderation) effect between reader knowledge and textual features. More specifically, the model compares the slope of regression plane for the predictor variable (reader knowledge) at low and high values of the textual feature variable. 
This study has also revealed that there was significant interaction model between grammatical knowledge and lexical frequency. There was a significant interaction effect, indicating that the relationship between grammatical knowledge and reading outcomes was moderated by text lexical frequency. Readers' grammatical knowledge accounted for $22 \%$ of the variance in high lexical frequency texts and $8 \%$ in low lexical frequency texts. The effect of grammatical knowledge was more evident for texts with easy vocabulary or high lexical frequency, but the effect of grammar was less observed when the texts contain low lexical frequency or difficult vocabulary. These findings may explain the divergence of findings regarding the role of grammatical knowledge in comprehending English texts.

Significant interaction between grammar and lexical frequency suggests that the ability to integrate word into other words at phrase and sentence level may depend on the ability to recognize words efficiently (Perfetti \& Stafura, 2014). Readers with low grammatical knowledge may only be able to activate their grammatical knowledge for texts with easy vocabulary but not for texts with difficult vocabulary. Understanding word meanings in the text is a prerequisite to applying the knowledge of sentence structure/grammatical knowledge in interpreting the meaning of the sentences and propositions in the text (Fender, 2001, 2003; Kintsch, 1998, 2005; Perfetti \& Stafura, 2014). The ability to recognize words in a text is fundamental for further word integration process during reading. Inability to identify word meanings and structure impede the ability to comprehend phrase and sentence meaning as well as proposition in a text. Thus, semantic processing is a key to sentence comprehension and discourse comprehension in general (Perfetti \& Stafura, 2014). The success of word-to-text integration requires high-quality word knowledge combining both form and meaning, a construct widely known as the Lexical Quality Hypothesis (Perfetti, 2007; Perfetti \& Hart, 2002). This knowledge is highly variable across individuals (Perfetti \& Stafura, 2014). Readers with high lexical quality are able to recognise words and integrate them with other words in the process of retrieving context-appropriate meanings, which in turn allows them to construct sentence propositions. Readers with low lexical quality will demonstrate "sluggish" or slow word integration process during text comprehension and will not always be successful in integrating a given word with the understanding of the text (Yang, Perfetti, \& Schmalhofer, 2005).

In sum, the findings were consistent with the discourse comprehension framework used in this study, in which a coherent mental representation of the 
text depends much on a reader's ability to successfully deal with lower level processes (word level processes) prior to their subsequent higher processes in comprehending a text. Having a large vocabulary and better knowledge of word forms and meanings not only frees up capacity for comprehension but also assists in driving meaning of new words and integrating words within an existing text representation. Readers with less vocabulary have a limited ability to understand a variety of texts since their vocabulary size and depth is inadequate for building text-based information needed for higher order comprehension processes.

\section{CONCLUSIONS}

There are several points that can be drawn from the findings of this study. First, readers' grammatical knowledge demonstrated a significant contribution in explaining L2 reading variance. Second, the lexical frequency of a text was found to play a great role in influencing L2 reading outcomes. Third, significant interaction was only evident between grammatical knowledge and lexical frequency in predicting L2 reading outcomes.

The findings give insight into the interplay of reader knowledge and textual features in predicting L2 reading outcomes. The relationship between readers' grammatical knowledge and text lexical frequency influences variability in reading outcomes. This specific finding explains why a certain type of text may be less or more challenging for readers at particular knowledge levels. The results of this study provide a foundation for further research on exploring the interaction of reader characteristics and textual features which may include more variables, such as topic familiarity and text genre. This kind of studies are needed to improve our understanding of the mechanisms involved in the development of second-language reading skills in various settings. Undoubtedly, one of those mechanisms is working memory capacity, which was not included in the study, while it has been widely recognized as an important constraint on L1 and L2 reading performance (Hannon, 2013; Harrington \& Sawyer, 1992). In addition, future studies can also explore the extent to which textual lexical difficulty and syntactic complexity affect L2 reading outcomes.

Overall, the findings of the study imply the need to carefully select the reading materials used in the classroom. The reading texts should not be too easy since simple texts do not convey much information to the readers. On the other hand, texts should not be too difficult as it discourages readers and makes 
them frustrated. Reading teachers or material designers should focus on the level of lexical difficulty and syntactic complexity that match the learners' level. This study also gives rise to a number of implications for reading pedagogy in Indonesia and beyond. The first is the importance of vocabulary knowledge in reading outcomes. This suggests that reading teachers and material designers should focus on building and familiarizing students with words in the text to develop their second-language reading skill.

\section{REFERENCES}

Anderson. (1984). Reading in a foreign language: A reading or a language problem? In J. C. Alderson \& A. H. Urquhart (Eds.), Reading in a Foreign Language (pp. 1-24). London: Longman.

Anderson, N. J. (2000). Assessing reading. Cambridge: Cambridge University Press.

Anthony, L. (2014). AntWordProfiler (Version 1.4.1) [Computer Software]. Tokyo, Japan: Waseda University. Retrieved from http://www.laurenceanthony.net/software/antwordprofiler/

Baron, R. M., \& Kenny, D. A. (1986). The moderator-mediator variable distinction in social psychological research: Conceptual, strategic, and statistical considerations. Journal of Personality and Social Psychology, 51(6), 1173-1182.

Barrot, J. S. (2013). Revisiting the role of linguistic complexity in ESL reading comprehension. 3L: The Southeast Asian Journal of English Language Studies, 19(1), 5-18.

Bernhardt, E. B. (2011). Understanding advanced second-language reading. New York, NY: Routledge.

Brown, D. (2012). The frequency model of vocabulary learning and Japanese learners. Vocabulary Learning and Instruction, 1(1), 20-28.

Brown, D. (2013). Types of words identified as unknown by L2 learners when reading. System, 41(4), 1043-1055.

Brysbaert, M., Buchmeier, M., Conrad, M., Jacobs, A. M., Bülte, J., \& Bühl, A. (2011). The word frequency effect: A review of recent developments 
and implications for the choice of frequency estimate. Experimental Psychology, 58(5), 412-424.

Cahyono, B. Y., \& Widiati, U. (2006). The teaching of EFL reading in the Indonesian context: The state of the art. TEFLIN Journal, 17(1), 36-56.

Chall, J. S., \& Dale, E. (1995). Readability revisited - The new Dale-Chall readability formula. Cambridge, MA: Brookline Books.

Cobb, T. (2010). Learning about language and learners from computer programs. Reading in a Foreign Language, 22(1) , 181-200.

Davy, E., \& Davy, K. (2002). Reading and vocabulary workbook for TOEFL exam. New Jersey: Thomson Arco.

Dubay, W. H. (2004). The principles of readability. Costa Mesa, CA: Impact Information.

Duffy, C. B., \& Mahnke, M. K. (1998). The Heinemann ELT TOEFL practice test. New York: Macmillan Publishers Limited.

Ellis, N. C. (2002). Frequency effects in language processing: A review with implications for theories of implicit and explicit language acquisition. Studies in Second Language Acquisition, 24(2), 143-188.

Fender, M. (2001). A review of L1 and L2/ESL word integration skills and the nature of L2/ESL word integration development involved in lower-level text processing. Language Learning, 51(2), 319-396.

Fender, M. (2003). English word recognition and word integration skills of native Arabic and Japanese-speaking learners of English as a second language. Applied Psycholinguistics, 24(2), 289-315.

Field, A. (2009). Discovering statistics using SPSS (3rd ed.). Thousand Oaks, California: SAGE Publications Inc.

Field, A. (2014). Discovering statistics using IBM SPSS statistics and sex and drugs and rock ' $n$ ' roll (4th ed.). Thousand Oaks, California: SAGE Publications Inc.

Flesch, R. (1948). A new readibility yardstick. Journal of Applied Psychology, $32(3), 221-233$. 
Flesch, R. (1951). How to test readability. New York: Harper.

Fry, E. (1968). A readability formula that saves time. Journal of Reading, 11(7), 513-516.

Fry, E. (1977). Fry's readability graph: Clarifications, validity, and extension to Level 17. Journal of Reading, 21(3), 242-252.

Goodman, K. S. (1967). Reading: A psycholinguistic guessing game. Journal of the Reading Specialist, 6(4), 126-135.

Gough, P. B. (1972). One second of reading. In J. F. Kavanagh \& I. G. Mattingly (Eds.), Language by ear and eye (pp. 331-358). Cambridge: Cambridge University Press.

Grabe, W. (1991). Current developments in second language reading research. TESOL Quarterly, 25(3), 375-406.

Grabe, W. (2009). Reading in a second language: Moving from theory to practice. New York: Cambridge University Press.

Graesser, A. C., McNamara, D. S., Louwerse, M. M., \& Cai, Z. (2004). CohMetrix: Analysis of text on cohesion and language. Behavior Research Methods, Instruments, \& Computers, 36(2), 193-202.

Graesser, A. C., McNamara, D. S., \& Louwerse, M. M. (2011). Methods of automated text analysis. In M. L. Kamil, P. D. Pearson, E. B. Moje \& P. P. Afflerbacj (Eds.), Handbook of Reading Research (Vol. IV, pp. 34-53). New York: Routledge.

Gunning, R. (1952). The technique of clear writing. New York, NY: McGrawHill.

Hannon, B. (2013). Understanding the relative contributions of lower-level word processes, higher-level processes, and working memory to reading comprehension performance in proficient adult readers. In D. E. Alvermann, N. J. Unrau, \& R. B. Ruddell (Eds.), Theoretical models and processes of reading (6th ed., pp. 840-885). Newark, DE: International Reading Association.

Harrington, M., \& Sawyer, M. (1992). L2 working memory capacity and L2 reading skill. Studies in Second Language Acquisition, 14(1), 25-38. 
Hayes, A. F. (2013). Introduction to mediation, moderation, and conditional process analysis: A regression-based approach. New York, NY: The Guilford Press.

Heatley, A., \& Nation, P. (2002). Range: A program for analysis of vocabulary in texts. Retrieved from http://www.vuw.ac.nz/lals/staff/paul-nation/ nation.aspx

Hsueh-chao, M. H., \& Nation, P. (2000). Unknown vocabulary density and reading comprehension. Reading in a Foreign Language, 13(1), 403-430.

Jeon, E. H., \& Yamashita, J. (2014). L2 reading comprehension and its correlates: A meta-analysis. Language Learning, 64(1), 160-212.

Kintsch, W. (1994). Text comprehension, memory, and learning. American Psychologist, 49(4), 294-303.

Kintsch, W. (1998). Comprehension: A framework for cognition. New York: Cambridge University Press.

Kintsch, W., \& Rawson, K. A. (2005). Comprehension. In M. Snowling \& C. Hulme (Eds.), The science of reading (pp. 209-226). Malden, MA: Blackwell.

Koda, K. (2005). Insights into second language reading: A cross-linguistic approach. New Yrok: Cambridge University Press.

Kweldju, S. (1996). English department students' interest and strategies in reading their content area textbooks. TEFLIN Journal, 8(1), 104-117.

Laberge, D., \& Samuels, S. J. (1974). Toward a theory of automatic information processing in reading. Cognitive Psychology, 6(2), 293-323.

Laboratorium Ilmu Humaniora Divisi Bahasa. (2014). TOEFL practice test. Malang: Fakultas Ilmu Budaya.

Laufer, B. (1989). What percentage of word lexis is essential for comprehension. In C. Lauren \& M. Nordman (Eds.), Special language: from human thinking to thinking machines (pp. 316-323). Clevedon: Multilingual Matters. 
Laufer, B. (1992). How much lexis is necessary for reading comprehension? In H. B. P. Arnaud (Ed.), Vocabulary and applied linguistics (pp. 126-132). London: MacMillan.

Linderholm, T, Everson, M. G., van den Broek, P., Mischinski, M., Crittenden, A., \& Samuels, J. (2000). Effects of causal text revisions on more- and less-skilled readers' comprehension of easy and difficult texts. Cognition and Instruction, 18(4), 525-556.

Lopez, A. L. (2008). To what extent does grammar knowledge account for competence in FL reading comprehension in university students? RESLA, 21, 181-200.

Masduqi, H. (2014). EFL reading in Indonesian universities: Perspectives and challenges in cultural contexts. Journal of Teaching and Education, 3(3), 385-397.

Milton, J. (2007). Lexical profiles, learning styles and the construct validity of lexical size tests. In H. Daller, J. Milton, \& J. Treffers-Daller (Eds.), Modelling and assessing vocabulary knowledge (pp. 47-58). Cambridge: Cambridge University Press.

Milton, J. (2009). Measuring second language vocabulary acquisition. Bristol: Multilingual Matters.

Murray, W. S., \& Forster, K. I. (2004). Serial mechanisms in lexical access: The rank hypothesis. Psychological Review, 111(3), 721-756.

Murtiningsih, S. R. (2014). Indonesian student teachers' beliefs and practices in teaching $L 2$ reading. (Doctoral dissertation, University of Oklahoma, Norman, Oklahoma, USA).

Nassaji, H. (2003). Higher-level and lower-level text processing skills in advanced ESL reading comprehension. The Modern Language Journal, 87(2), 261-276.

Nassaji, H. (2007). Schema theory and knowledge-based processes in second language reading comprehension: A need for alternative perspectives. Language Learning, 57(s1), 79-113.

Nation, P. (2006). How large a vocabulary is needed for reading and listening? The Canadian Modern Language Review, 63(1), 59-81. 
Nelson, J., Perfetti, C., Liben, D., \& Liben, M. (2012). Measures of text difficulty: Testing their predictive value for grade levels and student performance. Retrieved from http://www.ccsso.org/.../2012/measures oftextdifficulty_final.2012.pdf

Nurweni, A., \& Read, J. (1999). The English vocabulary knowledge of Indonesian university students. English for Specific Purposes, 18(2), 161175 .

Perfetti, C. A. (2007). Reading ability: Lexical quality to comprehension. Scientific Studies of Reading, 11(4), 357-383.

Perfetti, C. A., \& Hart, L. (2002). The lexical quality hypothesis. In L. Verhoeven (Ed.), Precursor of functional literacy (pp. 189-213). Amsterdam: John Benjamins Publishing Company.

Perfetti, C., \& Stafura, J. (2014). Word knowledge in a theory of reading comprehension. Scientific Studies of Reading, 18(1), 22-37.

Rayner, K., \& Duffy, S. A. (1986). Lexical complexity and fixation times in reading: Effects of word frequency, verb complexity, and lexical ambiguity. Memory and Cognition, 14(3), 191-201.

Read, J. (2000). Assessing vocabulary. Cambridge: Cambridge University Press.

Richards, J. C., \& Renandya, W. A. (2002). Methodology in language teaching: An anthology of current practice.Cambridge, MA: Cambridge University Press.

Rukmini. (2004, December). Genre analysis of the reading texts in the English textbook for high school students published by Balai Pustaka. Paper presented at the $52^{\text {nd }}$ TEFLIN International Conference, Palembang, Indonesia.

Rusfandi. (2013). Transfer of L2 English rhetorical structures of writing to L1 Indonesian by Indonesian EFL learners. (Doctoral dissertation, University of Queensland, Australia).

Sadtono, E. (1997). ELT development in Indonesia: A smorgasbord. In Sadtono (Ed.). The development of TEFL in Indonesia (pp. 1-19). Malang: Penerbit IKIP Malang. 
Sahiruddin. (2008). English in Indonesian Islamic higher education: Examining the relationship between performance in the Yes/No test and reading skills. Journal of Indonesian Islam, 2(2), 379- 403.

Sahiruddin. (2012, October). The effect of L1 and L2 glosses on vocabulary knowledge and reading comprehension in Indonesian EFL context. Paper presented at the ASIA TEFL International Conference, New Delhi, India.

Schmitt, N., Jiang, X., \& Grabe, W. (2011). The percentage of words known in a text and reading comprehension. The Modern Language Journal, 95(1), 26-43.

Skehan, P. (2009). Modelling second language performance: Integrating complexity, accuracy, fluency, and lexis. Applied Linguistics, 30(4), 510532 .

Shiotsu, T. (2010). Components of L2 reading: Linguistic and processing factors in the reading test performances of Japanese EFL learners. Cambridge: Cambridge University Press.

Shiotsu, T., \& Weir, C. J. (2007). The relative significance of syntactic knowledge and vocabulary breadth in the prediction of reading comprehension test performance. Language Testing, 24(1), 99-128.

Smagorinsky, P. (2001). If meaning is constructed, what is it made from? Toward a cultural theory of reading. Review of Educational Research, 71(1), 133-169.

Snow, C. E., \& Sweet, A. P. (2003). Reading for comprehension. In A. P. Sweet \& C. E. Snow (Eds.), Rethinking reading comprehension (pp. 111). New York: Guilford Press.

Stanovich, K. (1986). Matthew effects in reading: Some consequences of individual differences in the acquisition of literacy. Reading Research Quarterly, 21(4), 360-407.

Stenner, A. J., Horabin, I., Smith, D. R., \& Smith, M. (1988). Most comprehension tests do measure reading comprehension: A response to McLean and Goldstein. The Phi Delta Kappan, 69(10), 765-767.

van Gelderen, A., Schoonen, R., de Glopper, K., Hulstijn, J., Simis, A., Snellings, P., \& Stevenson, M. (2004). Linguistic knowledge, processing 
speed, and metacognitive knowledge in first- and second-language reading comprehension: A componential analysis. Journal of Educational Psychology, 96(1), 19-30.

van Gelderen, A., Schoonen, R., Stoel, R. D., de Glopper, K., \& Hulstijn, J. (2007). Development of adolescent reading comprehension in language 1 and language 2: A longitudinal analysis of constituent components. Journal of Educational Psychology, 99(3), 477-491.

Yamashita, J. (1999). Reading in a first and a foreign language: A study of reading comprehension in Japanese (the L1) and English (the L2). (Doctoral dissertation, Lancaster University, Lancashire, UK).

Yang, C. L., Perfetti, C. A., \& Schmalhofer, F. (2005). Less skilled comprehenders ERPs show sluggish word-to-text integration processes. Written Language \& Literacy, 8(2), 233-257.

Yap, M. J., Balota, D. A., Sibley, D. E., \& Ratcliff, R. (2012). Individual differences in visual word recognition: Insights from the English lexicon project. Journal of Experimental Psychology: Human Perception and Performance, 38(1), 53-79.

Zhang, D. (2012). Vocabulary and grammar knowledge in second language reading comprehension: A structural equation modeling study. The Modern Language Journal, 96(4), 558-575. 